\title{
Performance Evaluations in Audit Firms Evaluation Foci and Dysfunctional Behaviour
}

\author{
Riise Johansen, Thomas; Christoffersen, Jeppe
}

Document Version

Accepted author manuscript

Published in:

International Journal of Auditing

DOI:

10.1111/ijau.12079

Publication date:

2017

License

Unspecified

Citation for published version (APA):

Riise Johansen, T., \& Christoffersen, J. (2017). Performance Evaluations in Audit Firms: Evaluation Foci and Dysfunctional Behaviour. International Journal of Auditing, 21(1), 24-37. https://doi.org/10.1111/ijau.12079

Link to publication in CBS Research Portal

\section{General rights}

Copyright and moral rights for the publications made accessible in the public portal are retained by the authors and/or other copyright owners and it is a condition of accessing publications that users recognise and abide by the legal requirements associated with these rights.

Take down policy

If you believe that this document breaches copyright please contact us (research.lib@cbs.dk) providing details, and we will remove access to the work immediately and investigate your claim. 


\section{Performance Evaluations in Audit Firms: Evaluation Foci and Dysfunctional Behaviour}

\section{Thomas Riise Johansen and Jeppe Christoffersen}

Journal article (Accepted version)

This is the peer reviewed version of the following article: Performance Evaluations in Audit Firms : Evaluation Foci and Dysfunctional Behaviour. / Riise Johansen, Thomas; Christoffersen, Jeppe. In: International Journal of Auditing, Vol. 21, No. 1, 03.2017, p. 24-37, which has been published in final form at http://dx.doi.org/10.1111/ijau.12079.

This article may be used for non-commercial purposes in accordance with Wiley Terms and Conditions for Self-Archiving.

Uploaded to Research@CBS: December २017 


\title{
PERFORMANCE EVALUATIONS IN AUDIT FIRMS: EVALUATION FOCI AND DYSFUNCTIONAL BEHAVIOUR
}

\begin{abstract}
Previous research has only minimally examined the association between the behaviour and performance evaluations of individual auditors beyond the use of efficiency-focused evaluations. We examine the association between dysfunctional auditor behaviour and three evaluation foci: an efficiency focus, a client focus and a quality focus. Our results, which are based on questionnaire responses from 196 auditors, demonstrate that an efficiency focus is not associated with dysfunctional behaviour. A client focus is found to be associated with dysfunctional behaviour. Finally, and perhaps most importantly, our results show that it seems possible to limit dysfunctional behaviours through a quality focus in performance evaluations. Our results provide insights of use to practitioners and regulators on how performance evaluations may not only induce but also reduce dysfunctional auditor behaviours.
\end{abstract}

Keywords: audit firms, performance evaluation, dysfunctional behaviour 


\section{INTRODUCTION}

Audit firms and their auditors have public interest obligations pertaining to mandatory audits but are also private firms with commercial objectives, which instils a potential conflict between professional and commercial commitments (Carrington et al., 2013; Samuel et al., 2009; Suddaby et al., 2009; Wyatt, 2004; Zeff, 2003a; Zeff, 2003b). This delicate balance between commercialism and professionalism presents significant challenges for audit firms with regard to performance evaluation design.

Another challenge concerns how performance is measured. Audit firms have an interest in the efficient management of resources (staff) and therefore various measures of cost/effectiveness are prevalent in audit firms (Anderson-Gough et al., 2001). Following the coexistence of both professional and commercial commitments, audit firms also have interests in measuring performance along these dimensions. Professional performance may be understood as contributions to audit quality, but quality is difficult to measure as audits are credence goods-i.e. goods for which quality is difficult or extremely costly to observe, even after delivery (Knechel et al., 2013a). Commercial performance may be measured based on revenue contributions, but may also be more broadly related to client relationships. This implies that performance evaluations are likely to accommodate both quantitative and financial measures, included in formal evaluation systems, and more qualitative measures that may be perceived structurally or socially by auditors.

It is arguably unsurprising that concerns have been raised with regard to incentives oriented towards commercial objectives (Zeff, 2003b), and calls have been made for performance evaluation to address professional values (IFIAR, 2015). Thus, measures in auditor performance evaluation lead to auditor incentives that may induce or reduce risks of behaviours in conflict with professional standards (Knechel et al., 2013a; Zeff, 2003b). Such behaviours may be referred to as dysfunctional in the sense that they increase the risks of issuance of an incorrect audit opinion or of other flawed outcomes of audit engagements. 
Previous research suggests that particular ways of evaluating the performance of individual auditors produce perverse auditor incentives that may fuel their dysfunctional behaviours (Beekes et al., 2014; Otley \& Pierce, 1995; Otley \& Pierce, 1996a; Otley \& Pierce, 1996b; Pierce \& Sweeney, 2004). However, the empirical findings are mixed regarding the extent to which performance evaluations of auditors are associated with dysfunctional behaviour. Furthermore, previous research has focused only on the effects of particular efficiency-focused measures that may promote dysfunctional behaviours and not on other evaluation measures that may have similar effects or, potentially more interesting, on measures that may actually reduce dysfunctional behaviour.

To further refine and broaden knowledge on performance evaluations presented in previous research, we consulted previous studies to develop an understanding of how performance evaluations may take place (Beekes et al., 2014; Coram et al., 2004; Huddart, 2013; Knechel et al., 2013b; Otley \& Pierce, 1996a; Otley \& Pierce, 1996b; Pierce \& Sweeney, 2004; Pruijssers et al., 2013). However, the academic literature, in concentrating almost entirely on the efficiency focus, has not provided a comprehensive understanding of actual performance evaluation foci used in audit firms. Consequently, we were not able to construct measures of performance evaluation foci based entirely on the academic literature. Therefore, we engaged with a group of approximately 100 practitioners to deepen this understanding.

The practitioners, who were experienced staff auditors and managers participating in a course on research methods in accounting, were asked to discuss which measures they (or their colleagues) found of importance in formal or informal performance evaluations performed by their superiors. From these efforts, we collected a gross list of measures that individual auditors may encounter to varying extents in actual performance evaluations. These measures included specific metrics (e.g. the share of billable hours) and more subjective measures (e.g. customer evaluations). Our qualitative analysis of similarities between these measures, supported by confirmatory factor analyses (see the method section for further information), identified three different evaluation foci. These foci were labelled after what appeared to be their objective: an efficiency focus, a client focus or a quality focus. 
While the foci in some empirical contexts may be of varying relevance to either staff auditors or managers, we consider the foci to be meaningful for both staff-level auditors and managers in Denmark, which is the empirical setting for the survey. This is attributed to the low audit exemption threshold in Denmark, implying that numerous smaller businesses are subjected to mandatory audits. The fact that many auditors work with audit clients of varying sizes implies that even staff-level auditors work alone or with one or two other auditors in certain engagements, whereby they not only assume responsibility for the efficiency and quality of their own efforts, but also a considerable level of responsibility for the quality of the engagement and for the performance of client relationships. Thus we hypothesize that the efficiency focus and client focus are associated with an increase in dysfunctional behaviour at both the staff auditor and manager levels (H1-H2), while the quality focus limits it (H3). Using data collected through a survey, we find support for $\mathrm{H} 2$ that the client focus may promote dysfunctional behaviours. Furthermore, we find support for H3 and thus for the main tenet: that dysfunctional behaviour can be discouraged through performance evaluations.

This study contributes by elucidating the consequences of client-focused and qualityfocused evaluations and by demonstrating that efficiency-focused evaluations may not be as problematic as suggested in previous studies. More specifically, this study makes three significant contributions. Firstly, we document that efficiency-focused evaluations do not appear to be associated with dysfunctional behaviour. This finding suggests that performance evaluations in audit firms can include measures related to efficiency without escalating dysfunctional behaviours. Secondly, a broader set of performance evaluation measures is examined than in previous studies. The findings show that clientfocused performance evaluations fuel dysfunctional behaviour, and this paper thus supports concerns regarding the evaluation focus on client satisfaction and revenue from non-audit services. The paper also demonstrates that quality-focused evaluations may enhance auditor professionalism, and we thereby bring much needed nuances to extensive debates on incentive systems in audit firms, especially because previous debates have tended to depict such systems in opposition to public interests (Doty, 
2011; FRC, 2012; IAG, 2013; IFIAR, 2015; PCAOB, 2008; Zeff, 2003b). Thirdly, it is shown that the effects of performance evaluations on dysfunctional behaviours are mainly evident for the least experienced auditors. This may indicate that more experienced auditors are subjected more to social controls related to their socialization as professionals rather than to administrative controls in performance evaluation systems.

\section{PREVIOUS RESEARCH AND HYPOTHESES ON PERFORMANCE EVALUATIONS AND DYSFUNCTIONAL BEHAVIOURS}

\section{Performance Evaluations and Dysfunctional Behaviours in Audit Firms}

A strand of audit research has addressed behaviours that may be directly or indirectly associated with audit quality, including insufficient evidence-gathering, flawed audit procedures, inaccuracy, acceptance of invalid client explanations, the omission of required procedures, the underreporting of time, the documentation of procedures that have not been performed, and client overcharging (Alderman \& Deitrick, 1982; Beekes et al., 2014; Donnelly et al., 2003; Herrbach, 2001; Kelley \& Margheim, 1990; Lambert \& Agoglia, 2011; Otley \& Pierce, 1995; Otley \& Pierce, 1996a; Otley \& Pierce, 1996b; Pierce \& Sweeney, 2004; Pruijssers et al., 2013; Svanström, 2016). This behaviour has been referred to as dysfunctional behaviour (Kelley \& Margheim, 1990; Lambert \& Agoglia, 2011; Otley \& Pierce, 1996a; Pruijssers et al., 2013; Svanström, 2016), reduced audit quality behaviour (Coram et al., 2004; Coram et al., 2008; Svanberg \& Öhman, 2015) and quality-threatening behaviour (Beekes et al., 2014; Pierce \& Sweeney, 2006; Sweeney \& Pierce, 2004; Sweeney et al., 2013).

Given the severe consequences of dysfunctional behaviour, the causes of this type of behaviour have been subject to some investigation (e.g., Donnelly et al., 2003; Pierce \& Sweeney, 2004). Suggested antecedents include time pressure (Coram et al., 2004; Otley \& Pierce, 1996b; Svanström, 2016), audit firm governance practices (Pruijssers et al., 2013), characteristics of the audit review process (Lambert \& Agoglia, 2011), auditors' identification with clients (Svanberg \& Öhman, 2015) and performance evaluations (Beekes et al., 2014; Otley \& Pierce, 1996a; Pierce \& Sweeney, 2004). 
Only three previous studies have empirically responded to the debates on audit quality consequences of performance evaluations. In an early paper, Otley and Pierce (1996a) find no association between dysfunctional behaviour and a performance evaluation emphasis on meeting time budgets. More recently, Beekes et al. (2014) investigated this association in a specific UK audit firm and reported a significant positive association between being target-focused and quantitative in performance evaluations of auditors and dysfunctional behaviour. Finally, Pierce and Sweeney (2004) find that a budget orientation in performance evaluations is not associated with dysfunctional behaviour. However, they also find that an emphasis on what they refer to as non-accounting measures in performance evaluations causes reduced dysfunctional behaviours. Nonaccounting measures examined in their study include such diverse measures as the ability to communicate, client relationships, non-audit services, quality and technical abilities (Pierce \& Sweeney, 2004, p. 431). This study is very interesting because, to our knowledge, it is the only study showing that performance evaluations can discourage dysfunctional behaviour. However, it employs a very broad multi-item measure, and it is reasonable to expect that some measures may in fact have diluted or even counteracted this effect. For example, auditor perceptions of being evaluated on their capacities to sell non-audit services may be differently associated with dysfunctional behaviours compared to perceptions of being evaluated on technical abilities.

\section{Hypothesis Development}

We posit that performance evaluations may induce or reduce dysfunctional behaviour, depending on the evaluation focus. We present three evaluation foci in the following sections.

\section{The Efficiency Focus}

Time budgets and billable hours are the focus areas commonly employed in professional service firms, in which a focus on time inputs and on the efficient use of time appears to be essential to management control (Anderson-Gough et al., 2001; Cooper et al., 1996; Gendron \& Spira, 2009; Lewis \& Brown, 2012). Given the importance of time as the primary cost driver, previous research has focused on how, why and with what consequences this cost driver is managed within audit engagements 
(Alderman \& Deitrick, 1982; Beekes et al., 2014; Coram et al., 2004; Kelley \& Margheim, 1990; Lopez \& Peters, 2011; Otley \& Pierce, 1996b; Pierce \& Sweeney, 2004; Svanström, 2016). This body of research has identified that audit firms use time budgets, measure engagement profitability (whether fees cover costs), and emphasize the importance of time deadlines.

An emphasis on efficiency may, however, be counterproductive to the professional behaviours of auditors. Pressures to meet time budgets and to ensure the efficiency of audit engagements may cause auditors to, for example, skip time-consuming procedures or accept weak audit evidence. Evidence of these effects is presented in two recent studies that find time pressure to be a factor that reduces audit quality (Lopez \& Peters, 2011; Svanström, 2016). Likewise, empirical studies have shown that pressures to meet or beat time budgets or time deadlines compromise audit quality (Otley \& Pierce, 1996b; Pierce \& Sweeney, 2004). While at first glance such responsibilities seem to be of concern to managers with direct budget responsibilities, we expect, in line with previous research, that pressures to be efficient are likewise perceived by staff auditors who perform individual tasks within a pre-set number of hours or who are otherwise evaluated on how efficiently they perform.

Thus, we hypothesize the following:

H1. The prevalence of an efficiency focus in performance evaluations is positively associated with the dysfunctional behaviours of auditors.

\section{The Client Focus}

Previous research has primarily focused on evaluation measures and methods that are designed to align the incentives of individual auditors with the efficiency goals of an audit firm. However, commercialism in audit firms may be more nuanced than this, and evaluation measures may also be more outward-looking and related to, for example, practice development, winning and retaining clients, client satisfaction and the ability to sell services (Hooks et al., 1994; Pruijssers et al., 2013). 
The relevance of considering this type of client-focused evaluation is related to ways in which the profitability of audit firms depends on strong client relationships and, more specifically, to perceived increased pressures on auditors to maximize revenues from each client (Causholli et al., 2014). According to Zeff (2003b), for example, there has been a deterioration in professional values as 'the audit mentality at the top management of the firms was replaced by a consulting mentality, including a headlong drive for growth, profitability and global reach-business, not professional values’ (Zeff, 2003b: p. 280; see also Carrington et al., 2013; Wyatt, 2004). Indeed, we consider it likely that the behaviours of individual auditors are affected when an auditor is assessed on the ability to develop strong client relationships, to generate revenues from additional services sold and to attract new clients.

We believe that this impact is likely to occur regardless of an auditor's level of experience; partners may have decisive interactions with more central personnel in the client company, but managers and staff-level auditors, on the other hand, have frequent interactions with client staff (Gibbins et al., 2007; Sweeney \& Pierce, 2011). Furthermore, if a deterioration of professional values is taking place among audit partners, as suggested by Zeff (2003b), this is likely to spread along the hierarchy (Kornberger et al., 2011; Wyatt, 2004) (for example, because of the attention to partner promotion criteria among non-partners).

In line with this discussion, Trompeter (1994) shows in an experimental setting that it may impair audit partner objectivity and interfere with audit judgements when client retention is used as a performance measure in partner compensation schemes. Bennett and Hatfield (2013) find that staff-level auditors may engage in dysfunctional behaviours when auditors believe that a client would otherwise be annoyed. There is also considerable research and regulatory development focusing on the consequences of providing non-audit services to audit clients (Causholli et al., 2010; EU, 2014; Habib, 2012), and while the results of previous research are not unequivocal, there is a general agreement that non-audit services constitute a potential threat to auditor independence (Causholli et al., 2014; Habib, 2012; IFIAR, 2015). In particular, researchers have found that when there is a prospect of future benefits (e.g. client retention or clients 
buying additional services), auditor judgement and behaviours may be affected in relation to financial reporting quality (Causholli et al., 2014; Cohen \& Trompeter, 1998) or in evidence-gathering choices (Felix et al., 2005).

We suggest that a client focus employed in auditor evaluations may augment dysfunctional behaviours, as auditors may be concerned with pleasing clients and thus may be reluctant to challenge client explanations or to perform rigorous procedures that may upset client staff. Auditors may also avoid audit procedures that might reveal findings that client staff would not want to be revealed.

Based on the above discussion, we hypothesize the following:

H2. The prevalence of a client focus in performance evaluations is positively associated with dysfunctional auditor behaviours.

\section{The Quality Focus}

An audit is a good whose quality is difficult and costly for outsiders to assess (Knechel et al., 2013a). Furthermore, even if clients detect poor audit quality, they may have incentives to withhold information about it (Moizer, 1992). This also means that unlike other industries, audit firms cannot rely on user or client feedback on audit quality. Audit firms therefore have incentives to manage audit quality and, over the last few decades, audit firms have progressively developed within-firm quality arrangements (Bedard et al., 2008; Knechel et al., 2013a; Pruijssers et al., 2013). This is also encouraged by regulators and by the recent upsurge in audit quality inspections and the consequences thereof (Abbott et al., 2013; Carson et al., 2013). These developments create an impetus in audit firms to manage whether managers and staff-level auditors act in ways that are not subsequently criticized in inspections by regulators. This focus is based on the assumption that it is possible to curtail dysfunctional behaviours via control mechanisms. Such mechanisms may be amplified by incorporating evaluation measures that represent, for example, results from internal or external quality reviews, superiors' qualitative or quantitative assessments of individual professional competencies, or deviances from internal standards in audit firms' evaluations of 
individual auditors. These mechanisms have implications for everyone involved in audit services, including staff, managers, engagement partners and those involved in audit firm management who oversee audit services (IAASB, 2009).

Pierce and Sweeney (2004) present indicative evidence that it is possible to discourage dysfunctional behaviours through performance evaluations. As stated above, however, their multi-item measure covers both client- and quality-focused measures and thus does not identify the exact measure that has beneficial effects. In another study, Malone and Roberts (1996) find evidence among staff and senior auditors that individual auditor perceptions of the strength of quality assurance and control mechanisms are inversely related to dysfunctional behaviour. These results suggest that audit firms' commitment to audit quality may create expectations among auditors that rewards or punishmentseither in terms of pay, promotion or task allocation-are based on their contributions to audit quality. If this commitment is included in the performance evaluation design, it is likely that an auditor will, intentionally or unintentionally, act and make decisions in ways that are expected to convince quality inspectors or superiors of the quality of work undertaken. We therefore expect auditors who perceive an evaluation based on quality to be inclined towards following rigid and time-consuming procedures, and even those procedures that may potentially impair the auditor-client relationship.

Thus, our third hypothesis suggests that performance evaluations may in fact discourage dysfunctional behaviours. We hypothesize the following:

H3. The prevalence of a quality focus in performance evaluations is negatively associated with dysfunctional auditor behaviours.

\section{METHOD}

\section{Research Context and Data}

To obtain data for hypothesis testing, we conducted a survey targeting auditors in Denmark where we had unique access to survey respondents and thus a good chance of achieving high response rates and, as a result, low non-response bias levels. To ensure sufficient levels of variation in the variables of interest, we targeted a large proportion 
of audit firms in Denmark: this included the 'big 4' firms and most national affiliates of the other major international audit networks. We also included other mid-sized audit firms. In Denmark, audits are mandatory for companies that, over two sequential years, exceed two of the following limits: a turnover of DKK 8 million (USD 1.2 million), total assets of DKK 4 million (USD 0.6 million) and 12 employees. This low audit exemption threshold means that most auditors work with clients of varying sizes and that the number of individuals on engagement teams may vary from two (one partner and one manager/staff level auditor) to 20-25 individuals (the domestic component of the engagement team related to a large client).

Following guidelines on ways to obtain high quality data (Dillman, 2007; Huber \& Power, 1985), we encouraged participation by explaining the relevance of the research project (Huber \& Power, 1985). We obtained assistance from approximately 100 practitioners who attended a course in accounting research methods. These practitioners encouraged colleague participation, presumably resulting in higher quality responses and a high response rate, and thereby entailing a low risk of non-response bias. The survey questionnaire was administered by email from the research team to 616 auditors who had been identified by the course participants. The 616 auditors primarily included colleagues of the course participants and represented 39 different audit firms. After the final round of reminders was sent, 354 respondents had returned the questionnaire. In a post-hoc check of respondent capacities to answer questions of importance to this study, we excluded 27 respondents who were not employed in auditing positions and 24 respondents with less than one year of tenure and who thus displayed limited knowledge of the performance evaluation measures used to evaluate them. Finally, we excluded 78 signing auditors who were assumed to be evaluated and incentivized differently than less senior auditors, partly due to profit-sharing schemes at the partner level. We addressed missing observations through listwise deletion and omitted an additional 29 observations. We thus obtained 196 usable observations from 34 different firms, generating a usable response rate of 32 per cent. We consider this response rate to be sufficient and indeed good relative to similar studies (e.g., Pierce \& Sweeney, 2004). We suspect that this high response rate is in part a result of the engagement of course participants who championed the project with their respective firms. 
Though this high response rate lowered non-response bias risk, we assessed nonresponse bias risk using Armstrong and Overton's (1977) extrapolation procedure. This procedure is based on the assumption that subjects who do not respond readily (i.e. late respondents) are more similar to non-respondents than those who respond readily (i.e. early respondents). We split the sample in two based on response times and performed a t-test on differences between the two sample means across the items, thus addressing the hypothesized and control variables. The average $\mathrm{p}$ value for the differences was rather high at 0.51 , and only one pertaining to one of the three items of the variable reflecting client focus fell below a value of 0.05. Differences between the means of the remaining items used in the study were insignificant, indicating that differences were not systematic and that non-response bias effects did not appear to be present.

\section{Variables}

\section{Dependent Variable: Dysfunctional Behaviour}

As a starting point for the development of a measure for dysfunctional behaviour, we identified measures used in previous audit research. Otley and Pierce (1996a) adopted a combined measure for dysfunctional behaviour, as developed by Kelley and Margheim (1990). This multi-item measure, or adjusted versions of it, has subsequently been used in several studies (Beekes et al., 2014; Herrbach, 2001; Malone \& Roberts, 1996; Otley \& Pierce, 1996a; Pierce \& Sweeney, 2004) and mainly in studies on the behaviours of staff-level auditors, though some studies have also examined senior-level auditors (Beekes et al., 2014; Malone \& Roberts, 1996). The items that we include as acts of dysfunctional behaviour appear in the appendix (items a-c and f), where we also include the preamble given to respondents in relation to acts of dysfunctional behaviour. The preamble was inspired by social desirability theory (e.g. Nederhof, 1985), which predicts that auditors provide biased responses to questions about performing dysfunctional behaviours (see also Cohen et al., 1995). We therefore draw on the projective method of social desirability bias reduction (Fisher, 1993) and precede the list of dysfunctional behaviour acts with a preamble that shows our respondents that it is not uncommon for pressures to place auditors in situations where they 'have to' perform acts of dysfunctional behaviour. 
The dysfunctional behaviour measure includes two items that reflect premature signoff (Alderman \& Deitrick, 1982; Bedard et al., 2008). One (b) simply pertains to a situation where a required procedure is not followed, while the other (f) is a variant of this, as it refers to a case where procedures are specified through rigid or burdensome regulations. Previous studies have used other specific acts as indicators of premature signoff (e.g. accepting weak explanations from management). We relate these two items to procedures because contemporary auditors operate in a context whereby regulations and standards are operationalized in procedures manifested in methods, manuals, support systems and checklists. Regulators and administrative partners (e.g. risk management partners) will consider departures from such procedures as dysfunctional acts. Items a and c relate to situations where short-term targets are pursued to the detriment of longterm performance and to situations where actions go against an auditor's professional judgement, respectively. We also asked respondents about two additional situations (d and e) related to how individuals manage working time. Although the link to audit quality seems to be indirect, these two additional situations have been included as dysfunctional behaviour acts in previous research (Beekes et al., 2014). Therefore, we also included them in our initial six-item dysfunctional behaviour measure, but found via a confirmatory analysis (see the discussion and table below) that the conceptual disconnect with the other acts is mirrored in the empirical findings. Thus, our final measure of dysfunctional behaviour includes the four items of a-c and $\mathrm{f}$.

While some researchers have questioned the use of multi-item measures to reflect dysfunctional behaviours (Coram et al., 2004; Coram et al., 2008; Herrbach, 2001) on the grounds that insights can be gleaned from examining specific acts of dysfunctional behaviour, there is generally a broad consensus that dysfunctional behaviour acts are manifestations of dysfunctional behaviour, which in itself is considered to be a construct. This interpretation is supported by the fact that studies generally present high Cronbach's alphas for multi-item measures, indicating that individuals performing one dysfunctional behaviour act are likely to perform others. Thus, for the purpose of the primary analysis of this study, we interpret dysfunctional behaviour acts as manifestations of the dysfunctional behaviour construct and therefore combine 
responses on four acts into a multi-item measure for dysfunctional behaviour. However, as we acknowledge that it may be useful to focus on individual dysfunctional behaviour acts in some cases (Coram et al., 2004; Coram et al., 2008; Herrbach, 2001), we conduct a post-hoc analysis whereby all acts are considered individually as dependent variables. This post-hoc analysis also considers items $d$ and e, which were eliminated from our multi-item measure of dysfunctional behaviour.

\section{Antecedent Variables: Evaluation Foci}

From the start of this research project, we sought to obtain an understanding of how auditor performance evaluations may take place, and we sought to do so by scrutinizing the academic literature (Beekes et al., 2014; Coram et al., 2004; Huddart, 2013; Knechel et al., 2013b; Otley \& Pierce, 1996a; Otley \& Pierce, 1996b; Pierce \& Sweeney, 2004; Pruijssers et al., 2013). However, we found that the academic literature has focused almost entirely on the efficiency focus, and thus we were not able to construct measures reflecting the broader range of performance evaluation foci used in actual audit firms. Therefore, we engaged with a group of approximately 100 practitioners to assist us in these endeavours. The group excluded signing auditors and thus only included staff auditors and managers, all of whom were participants in a course on research methods in accounting. The participants were informed that the purpose of the discussion was to map the performance evaluation landscape and to provide a list of measures that may be in play when superiors conduct performance evaluations. The participants were then instructed to engage in a brainstorming exercise and to discuss which measures they (or their colleagues) considered to be of importance to performance evaluations performed by their superiors. The participants were not given a list of potential measures to discuss but were instead asked to consider anything that they believed to be of importance to their superiors. Furthermore, they were asked to discuss all measures regardless of whether these measures were visible in structural or social processes, as the two process types have been found to play significant roles individually as well as in tandem (Dirsmith et al., 1997; Pierce \& Sweeney, 2005; Westermann et al., 2015).

The specific product of these efforts was a gross list of measures that individual auditors may encounter to varying extents in actual performance evaluations. To avoid creating a 
lengthy questionnaire with almost duplicate questions, the identified evaluation measures were consolidated until we obtained 11 measures. Our analysis of the verbal contents of these 11 measures reflected our suggestions for three different evaluation foci: the efficiency focus, the client focus and the quality focus. These 11 measures were then included in the questionnaire. The measures are shown in Appendix 1 (items $\mathrm{a}-\mathrm{k})$. As the study seeks to address the performance evaluations of each individual auditor, each respondent was asked to assess measures used in evaluations of his or her own performance. The measures were randomly presented to each respondent through the questionnaire, and thus the order of presentation used did not induce expected interitem intra-measure correlation patterns. Still, our confirmatory factor analysis results do show such patterns, validating our initial measures.

\section{Control Variables}

We controlled for organizational commitment, which is assumed to influence dysfunctional behaviour (Beekes et al., 2014; Garcia \& Herrbach, 2010; Herrbach, 2001; Malone \& Roberts, 1996; Otley \& Pierce, 1996a). We initially formed a nineitem measure consistent with Meyer et al.'s (1993; 1991) approach, which has also been applied in previous audit research (Beekes et al., 2014; Garcia \& Herrbach, 2010; Stallworth, 2004). Our confirmatory factor analysis gave rise to a refinement through item elimination, resulting in a six-item measure (see the discussion and Table 1 below). We also included variables to control for contexts that are likely to be associated with dysfunctional behaviour. These include whether a firm is a 'big 4' firm (1) or not (big 4=0); each respondent's level of experience (representing different levels of professional socialization that may counteract dysfunctional behaviour), and whether an auditor is a manager (1) or a staff-level auditor (manager=0) (as increasing responsibility for output increases the consequences of, and thus lowers the likelihood of, dysfunctional behaviour). Managers are not qualified auditors but are responsible for other staff (e.g. staff auditors) during audit engagements. Staff auditors have at least one year of experience and may have several years of experience, as long as they do not assume responsibility for other staff. 
The items used to reflect the above variables were collected through a questionnaire (see Appendix 1). The first draft of the questionnaire was scrutinized by fellow academics. This review led to questions being rephrased, and terms that were considered ambiguous were reconsidered. Next, the adjusted version was tested on the audit practitioners attending the course, as well as on academic colleagues. This final step resulted in only minor revisions being made to the questionnaire. The test respondents were not included in the final sample.

\section{Measure Validation}

We evaluated the multi-item measures by including all of the assumed constructs in a measurement model to be tested via Maximum Likelihood estimation through the SAS procedure Proc Calis. Table 1 reports standardized loadings and composite reliability scores for each multi-item variable. The table shows that our initial measures of dysfunctional behaviour and organizational commitment included items with standardized loadings falling below the 0.4 limit recommended by Hair et al. (2011). Therefore, we individually eliminated items with the lowest loadings until we arrived at our final measures, none of which contained items with loadings of less than 0.4. Thus, the final measures only include items with loadings in excess of 0.4 and generally have composite reliabilities of well above the suggested 0.7 limit (e.g. Hair et al., 2011). While our efficiency focus measure falls just slightly below this limit, we use this measure with the four initially suggested items as we cannot secure improvements by eliminating items.

$<<$ Insert Table 1 about here $>>$

To assess the discriminant validity of each multi-item variable, we squared each variable's correlations with the other multi-item variables and compared these against the relevant average variance extracted (AVE) for all variables (not tabulated). All squared correlations (ranging from 0 to 0.09 ) were considerably below all of the AVEs (ranging from 0.36 to 0.53 ), suggesting that all of the measures reflect different constructs (Fornell \& Larcker, 1981). We then performed Harman’s single-factor test using a CFA procedure to appraise the level of common method variance in the data 
(not tabulated). The AVE for this latent variable is at 0.16 , which is much lower than the lowest AVE of the multi-item measures, and common method variance thus does not appear to be the main cause of our data pattern (Korsgaard \& Roberson, 1995; Podsakoff et al., 2003).

\section{RESULTS}

\section{Primary Analysis}

Table 2 depicts the descriptive statistics for our data. Panel A presents the range, mean, standard deviation and Cronbach's alpha for the variables of interest. The statistics show that actual ranges for the multi-item measures resemble the theoretical ranges, indicating the needed variation in variables. They also show that using Cronbach's alpha leads us to the same conclusions on composite construct validity as the composite reliabilities based on factor loadings. Furthermore, the descriptive statistics show that 47 per cent of the respondents work in the big 4 firms, and 48 per cent are managers (52 per cent are staff auditors). The large number of usable responses and almost equal distribution of auditor positions provide us with an (unexpected) opportunity to test our hypotheses on two sub-samples that consist of auditors in the two different positions. We pursue this opportunity to provide deeper insights into the applicability of our findings across different positions that may entail both different uses and effects of evaluation foci. Therefore, we also provide some basic descriptive statistics on these sub-samples (all but correlations). Overall, we found no major differences between the samples. This provides empirical support for testing our analyses across different auditor ranks, as auditors within both ranks seem to believe that they are evaluated based on all three foci.

$<<$ Insert Tables 2 and 3 about here $>>$

We used OLS regression models to test hypotheses H1, H2, and H3. Table 3 shows the results of our regressions. Focusing first on the regressions for the full sample, it is evident that the model is highly significant, with an F value of 6.58. The coefficients for the variables of relevance to our hypotheses show that while H1 (regarding the efficiency focus' positive association with dysfunctional behaviour) receives no support 
( $\beta=0.04, p>0.10$ ), there is strong support for H2 (regarding the client focus' positive association with dysfunctional behaviour) $(\beta=0.44, p<0.01)$ and for H3 (regarding the quality focus' negative association with dysfunctional behaviour) $(\beta=-0.35, p<0.01)$.

Turning to the tests performed on the two sub-samples, we first see that both models are significant, with F values of 3.77 and 5.95 for staff auditors and managers, respectively. The higher explanatory power in the manager sub-sample seems to be driven by two of the control variables: Big 4 and experience. For the manager sub-sample, both of these variables reduce dysfunctional behaviour, while they seem to be of less importance in the staff auditor sub-sample. We believe that manager interactions with clients present higher stakes whereby withstanding pressures becomes more salient. It is likely easier for managers to withstand pressures when they represent the Big 4 firms and when they have more experience (Bamber \& Iyer, 2007; Svanberg \& Öhman, 2015; Sweeney \& Pierce, 2011). Focusing on the coefficients pertaining to our hypotheses, we see that H1 is supported in none of the sub-samples, in line with the full sample test. Next, we see that support for $\mathrm{H} 2$ appears to be driven by staff auditors, for whom this relation is highly significant $(\beta=0.53, p<0.01$ ), while the coefficient for the manager sub-sample is of the expected direction but is insignificant at conventional significance levels. H3 receives strong support in both the staff auditor sub-samples $(\beta=-0.33, p<0.01)$ and the manager sub-sample $(\beta=-0.37, p<0.01)$.

It is somewhat surprising that $\mathrm{H} 1$ is supported in neither the full sample regression nor the sub-sample regressions. We feel unable to explain convincingly the lack of support, but do note that the efficiency focus, unlike the client focus, does not directly relate to human interactions with clients but rather to the somewhat formalized internal expectations in the audit firm. This also implies that auditors can to some extent meet these internal and formalized expectations by shifting available time from overbudgeted engagements to engagements where the budget is less generous. This may provide some flexibility to avoid reducing the effort below what is needed to perform audit work of sufficient quality. 
There are two likely reasons for the lack of support for $\mathrm{H} 2$ found in the manager subsample. One pertains to measurement problems; another pertains to the hypothesized effect being absent. These two possible reasons are explored below.

The measure of dysfunctional behaviour has mainly been applied in studies involving relatively inexperienced staff auditors, which may mean that the measure does not represent acts of dysfunctional behaviour that managers might engage in (Exceptions to this are Beekes et al., 2014; Malone \& Roberts, 1996; Svanberg \& Öhman, 2015). However, the Cronbach's alpha, mean and standard deviation across the two subsamples are on a par, indicating equivalent validity and relevance. Svanberg and Öhman (2015) likewise use a measure for dysfunctional behaviours that is similar across different auditor ranks and find that such behaviours appear roughly as frequently in both staff auditor and manager/partner groups. The same conclusion cannot be reached for the explanatory variable client focus, for which the Cronbach's alpha shows a difference between the two sub-samples. More specifically, the findings indicate that the measure used is more applicable to the staff auditor sub-sample, and this may to some extent explain the lack of support for $\mathrm{H} 2$ found for the manager sub-sample.

While measurement problems may account for some of the lack of support for H2, we also consider it possible that the hypothesized effect may be absent or at least weaker in the manager sub-sample. This assertion is in line with expectations that managers feel more accountable and responsible for professional behaviour within the audit firm. Furthermore, it is line with previous research finding that higher ranked (or more experienced) auditors are better than lower ranked (or less experienced) auditors at coping with pressures to exploit potential client business opportunities (Moreno \& Bhattacharjee, 2003) or with pressures to accept client preferences (Bamber \& Iyer, 2007; Svanberg \& Öhman, 2015). In this vein, it has been suggested that social controls and self-control are typical characteristics of within-firm control in professional service firms (e.g. audit firms), although it appears that administrative controls (including metrics use in performance evaluations) are being used more frequently (Brivot, 2011). ${ }^{1}$

\footnotetext{
${ }^{1}$ The distinction between administrative, social and self-controls is adopted by Brivot from Hopwood (1974).
} 
Social controls stem from being a member of a group that exerts control on member behaviours, which is characteristic of auditors who must undergo theoretical and practical training to shape the individual as a professional (Aranya \& Ferris, 1984; Covaleski et al., 1998). This socialization process is likely to generate some resistance to pressures from administrative controls (Covaleski et al., 1998), as it represents a form of oversight and influence by a community of peers (Almer et al., 2005). The social controls associated with professional commitment may therefore mitigate dysfunctional behaviours (Aranya \& Ferris, 1984; Covaleski et al., 1998) and such effects are expected to occur more often (socialization) as an individual gains more experience.

\section{Post-hoc Analysis}

Acknowledging that insights may be gleaned from examining specific dysfunctional behavioural acts (Coram et al., 2004; Coram et al., 2008; Herrbach, 2001), we conduct a post-hoc analysis whereby the regression pertaining to $\mathrm{H} 1-\mathrm{H} 3$ is rerun with each of the individual items of the multi-item measure of dysfunctional behaviour as the dependent variables. As previous contributions have used all six of our initial items, we perform regressions on all of these and not only the four used in our final measure. The results of the regressions performed on the full sample are presented in Table 4.

$<<$ Insert Table 4 about here $>>$

While the regression results shown in Table 4 should be interpreted with care, given the high measurement error risks related to single-item measures, we do believe that some interesting results appear. First, we note that once again items d and e stand out, this time by showing no association with the suggested explanatory variables. Item $d$ relates to the act of 'being unable to record all the time spent on the work that is assigned to you' and the model used to explain it is insignificant. Item e relates to 'having to stay longer hours in the office to indicate to your superiors or colleagues that you are working hard' and is explained only by experience, the coefficient for which indicates that more experienced auditors experience less pressure to maintain a persona of a hardworking auditor. It is noteworthy that these two items are also distinct from the other four items by not intuitively being related to audit quality, and given that our 
results also indicate that they are acts that are not generally affected by the same explanatory variables, they are also likely to be acts that are not related to the same behaviours. Studies based on qualitative methods have found that such acts are common because time is used symbolically in audit firms (Coffey, 1994) and because careers in these firms require the 'active engagement with the politics of time' (Anderson-Gough et al., 2001). It may therefore be that these acts are to be classified as social norms rather than dysfunctional behaviours. We therefore suggest that these items used to reflect dysfunctional behaviour acts in previous research (e.g., Bedard et al., 2008; Beekes et al., 2014; Donnelly et al., 2003; Otley \& Pierce, 1996a) are reconsidered in future studies.

The remaining four items are explained in line with our main tests-i.e. hypotheses 2 and 3 are supported based on these individual regressions in the same manner as for the multi-item measure of dysfunctional behaviour. From the perspective of regulators and risk management partners in audit firms, it is remarkable that the results are evident for items b and f, both of which are related to avoiding or skipping audit procedures. Such acts are arguably the most critical for audit quality, and therefore it is interesting that they can be affected both negatively and positively by performance evaluations. Nontabulated regressions on the sub-samples support the previous finding that results for the client focus employed in evaluations are primarily driven by the sub-sample consisting of staff auditors.

In our last post-hoc analysis, we sought to determine whether the results may have been driven by respondents from a few audit firms. In doing so, we tested our hypotheses on two sub-samples consisting of 107 respondents from five firms (each employing 12 or more of our respondents) and 89 respondents from the remaining 29 firms (each employing seven or fewer of our respondents). The (untabulated) results show that the results of our main analysis are repeated in both sub-samples-i.e. hypotheses 2 and 3 are supported while hypothesis 1 is not. 


\section{CONCLUSION}

Previous studies have neglected the association between performance evaluations of auditors and dysfunctional behaviours beyond research on the extent to which efficiency-focused evaluations are associated with dysfunctional behaviour (Beekes et al., 2014; Otley \& Pierce, 1996a; Pierce \& Sweeney, 2004). To develop a more complete understanding of this association, we first identified an array of evaluation measures that are commonly used in audit firms. We then identified three different evaluation foci: the efficiency focus, the client focus and the quality focus. Following this step, we developed hypotheses regarding the impact of each focus on dysfunctional behaviour (H1-H3). Finally, we tested these hypotheses on data obtained through a survey administered to a large sample of auditors. The hypotheses were supported, except for H1, which was related to the efficiency focus. Tests performed on two subsamples consisting of staff auditors and managers showed that support for our hypotheses primarily existed in the staff auditor sub-sample.

Our study makes three contributions. Firstly, we show that the adverse side-effects of an efficiency focus are not present in our sample. Previous research (Beekes et al., 2014; Otley \& Pierce, 1996a; Pierce \& Sweeney, 2004) is therefore not supported, as the results of this study indicate that performance evaluations in audit firms may include efficiency metrics without a fear of escalating dysfunctional behaviour. The second contribution pertains to the fact that we examine a broader set of performance measures than those explored in previous studies. In doing so, we demonstrate that a client focus is associated with dysfunctional behaviour and that a quality focus is associated with less dysfunctional behaviour. This supports the suggestion made by Pierce and Sweeney (2004), that certain performance evaluation designs may also counteract dysfunctional behaviour. As such, the study contributes with a balanced understanding of within-firm pressures and follows Knechel et al. (2013a), who highlight that it is important to understand both negative and positive effects of within-firm pressures on audit quality (e.g. via performance evaluations).

Finally, as a third contribution, we show how issues related to performance evaluations and dysfunctional behaviour are more prevalent for lower ranked auditors. Previous 
research has tended to collect responses from auditors with few years' experience, ${ }^{2}$ whereas respondents participating in this study had roughly eight years' experience on average. We show that our findings for the sub-sample with the least experienced auditors (staff auditors with a mean experience level of just over five years) are different from the findings for the manager sub-sample (with a mean experience level of just over ten years). It may be reassuring that the problematic association between metrics use and dysfunctional behaviour diminishes when auditors climb the hierarchy, as those auditors who are held more responsible for engagements are less susceptible to the adverse impacts of metrics use. However, the relevance of our findings is underscored by the fact that a large proportion of audit work is carried out by staff-level auditors (Gendron \& Spira, 2009; Sweeney \& Pierce, 2011). Francis (2004) identifies the potential mismatch between rewards (individual level) and risks (firm level) as a key challenge for performance evaluations, as auditors may be encouraged to pursue activities that may be individually rewarding but that at the same time are risky to the audit firm, but not to themselves. The results for the client focus in evaluation suggest that the evaluation mechanisms put in place for lower level auditors create similar incentives which also reward activities that are risky, and that auditors do react to these incentives. The results even indicate that this effect is stronger for staff auditors than for managers. Thus, as shown in some previous studies (Bamber \& Iyer, 2007; Moreno \& Bhattacharjee, 2003; Svanberg \& Öhman, 2015), less experienced auditors are more prone to follow client pressures. Reasons for this may be that less experienced auditors lack understanding of how to approach a client and are insecure in auditor-client interactions (Sweeney \& Pierce, 2011).

Several implications can be derived from this study. We suggest that regulators and audit firms pay careful attention to the performance evaluations of individual auditors and that they should in particular discourage distinctive client focus traits during performance evaluations and attempt to develop guidelines on ways to apply a quality focus. We argue that client-focused performance evaluations should receive more attention, especially relative to the apparently less harmful use of efficiency-focused

\footnotetext{
${ }^{2}$ For example, the mean experience in Otley and Pierce (1996b) was 3.5 years.
} 
evaluations. While our results highlight the downsides of tying administrative controls to the commercial goals of audit firms, they also demonstrate that it is possible to design performance evaluations that augment audit quality. These implications are consistent with recent debates in policy-making arenas. The working group on audit firm governance and incentives under the PCAOB Investor Advisory Group, for example, stresses the link between quality measures and auditor evaluations (IAG, 2013). Likewise, as part of their audit firm inspections, public oversight bodies have identified auditor performance evaluations as essential to audit quality and have suggested that auditors be evaluated on audit quality criteria (e.g., FRC, 2012; FRC, 2014; FRC, 2015; IFIAR, 2015; PCAOB, 2008). For those in charge of quality and risk management within audit firms, our findings on quality-based evaluations are encouraging and, together with a heightened external focus on quality inspections (Carson et al., 2013), they create within-firm incentives to follow the above mentioned calls made in the policy arena to link evaluations with quality measures.

This study has limitations pertaining to the depth and breadth of knowledge produced. The most noteworthy limitation pertaining to the depth of knowledge produced is attributed to the fact that we base our empirical analyses on a survey and therefore the validity of our analyses, conclusions and suggested implications is subject to the limitations inherent in the survey methodology.

One typical limitation of the survey methodology may be that the sample from which the survey results are obtained does not represent the population, which may give rise to biased results. In our case, the sample was selected with the aid of participants in a course on research methods in accounting. The course participants championed the survey amongst colleagues and those colleagues agreeing to participate became the survey population. Thus, while we have a very low fraction of non-responses in that sample, a bias may have resulted from the sample construction. For instance, it may be that those who agreed to be part of the survey sample are those auditors who are less subject to time pressure. Given that the efficiency focus is more likely to produce perverse effects when an auditor is subject to time pressure, we would expect that an underrepresentation of such pressured auditors would affect the estimated effect of the 
efficiency focus. Thus, the lack of support found for $\mathrm{H} 1$ may be due to a bias in our survey sample. This naturally means that this lack of support should not be relied upon blindly in policy-making contexts without further research addressing this issue.

Another typical limitation of the survey methodology concerns the fact that when it is used as the sole source of data, it can produce common method variance, causing spurious correlations. While our Harman's single factor test suggests that common method variance is not a dominant cause of the data patterns found in this study, we cannot rule out that our tests are affected to a small extent.

A final limitation related to the survey method concerns internal and external validity. As for internal validity, a prominent concern is that we believe that we have measured auditors' perceptions of three different evaluation foci, and even though we can use CFA to support the notion that we in fact measured three different constructs, we cannot be certain that all knowledgeable readers would agree upon the three labels that we have assigned to these. In fact, we are quite certain that they would not, particularly because two of the foci have not been addressed empirically in academic studies prior to the present study. Thus, internal validity is an issue to consider when interpreting our findings. This also means more work should be done to empirically and conceptually hone the measures presented in this study before full confidence in the measures and the resultant findings can be achieved. Furthermore, even if internal validity is satisfactory, external validity may not be so, as our study takes place in the setting of only one country and results may therefore not reproduce themselves in other countries with different regulatory and institutional settings, and different cultural norms. In particular, the relevance across staff auditors and managers may not prevail in any country. Follow-up studies comparing findings in different countries would corroborate external validity.

Our use of CFA supports that we have measured auditors' perceptions of three different evaluation foci, but we still acknowledge that the results may not be instrumentally adopted into formal performance evaluation designs. In fact, we cannot identify the specific measures being used, and we only assume that these are strongly associated 
with our measure-namely, the auditors' perceptions thereof. As a consequence of this assumption, our results may not be as easily applied by policy-makers and audit firms as suggested above. For instance, it may be difficult to strike an optimal balance when selecting evaluation measures to produce appropriate incentives for each individual auditor. This difficulty, in turn, suggests that future research should investigate the relationship between the actual use of evaluation measures and auditor perceptions. How does this relationship vary from one auditor to another, and what causes the variations? Of note here is the fact that while we developed measures that we considered to be applicable to staff auditors and managers, Cronbach's alpha values for client and efficiency foci indicate that the measures are more applicable to staff auditors. Thus, future research efforts should aim to develop these measures for different levels, as these may be slightly different.

The most noteworthy limitation pertaining to the breadth of knowledge produced through this study concerns the fact that we focus on the effects of individual evaluation foci. This limitation suggests that no knowledge is produced regarding nuances in the circumstances under which some of these effects may be stronger or weaker. Examples of interesting moderating factors could include audit firm structures, team structures, audit tasks and time pressure. The latter aspect regarding time pressure is particularly crucial, as an efficiency focus within evaluations is most likely to induce dysfunctional behaviours when an auditor senses a time pressure. Indeed, the absence of support for H1 may thus, to some extent, be explained by the fact that our sample underrepresents auditors subject to time pressure. In light of this, time pressure may be an important moderator.

For future research, this study presents the immediate implication that a broader range of evaluation foci and their interactions must be considered when their effects are investigated-in particular, the possibility that some elements of incentive systems (in given circumstances) may not be harmful while others are requires further attention. Which elements are harmful and which are not? Under which circumstances does this apply? Within this context, future conceptual and empirical work on the association 
between incentive systems and audit quality should focus on the prospect of providing auditors with quality incentives. 


\section{REFERENCES}

Abbott, L. J., Gunny, K. A., \& Zhang, T. C. (2013), 'When the PCAOB talks, who listens? Evidence from client firm reaction to adverse, GAAP-deficient PCAOB inspection reports', Auditing: A Journal of Practice and Theory, Vol. 32, No. 2, pp. 131.

Alderman, C. W. \& Deitrick, J. W. (1982), 'Auditors' perceptions of time budget pressures and premature sign-offs: A replication and extension', Auditing: A Journal of Practice \& Theory, Vol. 1, No. 2, pp. 54-68.

Almer, E. D., Higgs, J. L., \& Hooks, K. L. (2005), 'A theoretical framework of the relationship between public accounting firms and their auditors', Behavioral Research in Accounting, Vol. 17, No. 1, pp. 1-22.

Anderson-Gough, F., Grey, C., \& Robson, K. (2001), 'Tests of time: organizational time-reckoning and the making of accountants in two multi-national accounting firms', Accounting, Organizations and Society, Vol. 26, No. 2, pp. 99-122.

Aranya, N. \& Ferris, K. R. (1984), 'A reexamination of accountants' organizationalprofessional conflict', The Accounting Review, Vol. 59, No. 1, pp. 1-15.

Armstrong, J. S. \& Overton, T. S. (1977), 'Estimating nonresponse bias in mail surveys', Journal of marketing research, Vol. 14, No. 3, pp. 396-402.

Bamber, E. M. \& Iyer, V. M. (2007), 'Auditors' identification with their clients and its effect on auditors' objectivity', Auditing: A Journal of Practice \& Theory, Vol. 26, No. 2, pp. 1-24.

Bedard, J. C., Deis, D. R., Curtis, M. B., \& Jenkins, J. G. (2008), 'Risk monitoring and control in audit firms: A research synthesis', Auditing: A Journal of Practice \& Theory, Vol. 27, No. 1, pp. 187-218.

Beekes, W., Otley, D., \& Ururuka, V. (2014), 'Factors influencing quality threatening behaviour in a big four accounting firm', Available at SSRN 2462456. 
Bennett, G. B. \& Hatfield, R. C. (2013), 'The effect of the social mismatch between staff auditors and client management on the collection of audit evidence', The Accounting Review, Vol. 88, No. 1, pp. 31-50.

Brivot, M. (2011), 'Controls of knowledge production, sharing and use in bureaucratized professional service firms', Organization Studies, Vol. 32, No. 4, pp. 489-508.

Carrington, T., Johansson, T., Johed, G., \& Öhman, P. (2013), 'An empirical test of the hierarchical construct of professionalism and managerialism in the accounting profession', Behavioral Research in Accounting, Vol. 25, No. 2, pp. 1-20.

Carson, E., Simnett, R., \& Vanstraelen, A. (2013) 'Auditing the auditors: An international analysis of the effectiveness of national inspection regimes on audit quality', Presented at the EARNET conference.

Causholli, M., Martinis, M. D., Hay, D., \& Knechel, W. R. (2010), 'Audit Markets, Fees and Production: Towards an integrated view of empirical audit research', Journal of Accounting Literature, Vol. 29, No. 1, pp. 167-215.

Causholli, M., Chambers, D. J., \& Payne, J. L. (2014), 'Future Non-Audit Service Fees and Audit Quality', Contemporary Accounting Research, Vol. 31, No. 3, pp. 681-712.

Coffey, A. J. (1994), 'Timing is Everything; Graduate Accountants, Time and Organizational Commitment', Sociology, Vol. 28, No. 4, pp. 943-956.

Cohen, J. R., Pant, L. W., \& Sharp, D. J. (1995), 'An Exploratory Examination of International Differences in Auditors' Ethical Perceptions', Behavioral Research in Accounting, Vol. 7, No. 1, pp. 37-64.

Cohen, J. R. \& Trompeter, G. (1998), 'An Examination of Factors Affecting Audit Practice Development', Contemporary Accounting Research, Vol. 15, No. 4, pp. 481504.

Cooper, D. J., Hinings, B., Greenwood, R., \& Brown, J. L. (1996), 'Sedimentation and transformation in organizational change: The case of Canadian law firms', Organization Studies, Vol. 17, No. 4, pp. 623-647. 
Coram, P., Glavovic, A., Ng, J., \& Woodliff, D. R. (2008), 'The Moral Intensity of Reduced Audit Quality Acts', Auditing: A Journal of Practice \& Theory, Vol. 27, No. 1, pp. 127-149.

Coram, P., Ng, J., \& Woodliff, D. R. (2004), 'The Effect of Risk of Misstatement on the Propensity to Commit Reduced Audit Quality Acts under Time Budget Pressure', Auditing: A Journal of Practice \& Theory, Vol. 23, No. 2, pp. 161-169.

Covaleski, M. A., Dirsmith, M. W., Heian, J. B., \& Samuel, S. (1998), 'The Calculated and the Avowed: Techniques of Discipline and Struggles over Identity in Big Six Public Accounting Firms', Administrative Science Quarterly, Vol. 43, No. 2, pp. 293-327.

Dillman, D. A. (2007), Mail and internet surveys: The tailored design method, Hoboken, New Jersey: John Wiley \& Sons Inc.

Dirsmith, M. W., Heian, J. B., \& Covaleski, M. A. (1997), 'Structure and agency in an institutionalized setting: The application and social transformation of control in the Big Six', Accounting, Organizations and Society, Vol. 22, No. 1, pp. 1-27.

Donnelly, D. P., Quirin, J. J., \& O'Bryan, D. (2003), 'Auditor acceptance of dysfunctional audit behavior: An explanatory model using auditors' personal characteristics', Behavioral Research in Accounting, Vol. 15, No. 1, pp. 87-110.

Doty, J. R. (2011). Rethinking the Relevance, Credibility and Transparency of Audits. Speech at the SEC and Financial Reporting Institute 30th Annual Conference, Pasadena, CA.

EU (2014). Regulation (EU) No 537/2014 of the European Parliament and of the Council of 16 April 2014 on Specific Requirements regarding Statutory Audit of Public-Interest Entities. European Union.

Felix, W. L., Gramling, A. A., \& Maletta, M. J. (2005), 'The influence of nonaudit service revenues and client pressure on external auditors' decisions to rely on internal audit', Contemporary Accounting Research, Vol. 22, No. 1, pp. 31-53. 
Fisher, R. J. (1993), 'Social desirability bias and the validity of indirect questioning', Journal of consumer research, Vol. 20, No. 2, pp. 303-315.

Fornell, C. \& Larcker, D. F. (1981), 'Evaluating structural equation models with unobservable variables and measurement error', Journal of marketing research, Vol. 18, No. 1, pp. 39-50.

Francis, J. R. (2004), 'What do we know about audit quality?', The British Accounting Review, Vol. 36, No. 4, pp. 345-368.

FRC (2012). Audit Quality Inspections: Annual Report 2011/12. Financial Reporting Council, London.

FRC (2014). Deloitte LLP: Audit Quality Inspection. Financial Reporting Council, London.

FRC (2015). BDO LLP: Audit Quality Inspection. Financial Reporting Council, London.

Garcia, A. \& Herrbach, O. (2010), 'Organisational commitment, role tension and affective states in audit firms', Managerial Auditing Journal, Vol. 25, No. 3, pp. 226239.

Gendron, Y. \& Spira, L. F. (2009), 'What Went Wrong? The Downfall of Arthur Andersen and the Construction of Controllability Boundaries Surrounding Financial Auditing', Contemporary Accounting Research, Vol. 26, No. 4, pp. 987-1027.

Gibbins, M., McCracken, S. A., \& Salterio, S. E. (2007), 'The Chief Financial Officer's Perspective on Auditor-Client Negotiations', Contemporary Accounting Research, Vol. 24, No. 2, pp. 387-422.

Habib, A. (2012), 'Non-Audit Service Fees and Financial Reporting Quality: A MetaAnalysis', ABACUS, Vol. 48, No. 2, pp. 214-248.

Hair, J. F., Ringle, C. M., \& Sarstedt, M. (2011), 'PLS-SEM: Indeed a silver bullet', The Journal of Marketing Theory and Practice, Vol. 19, No. 2, pp. 139-152. 
Herrbach, O. (2001), 'Audit quality, auditor behaviour and the psychological contract', European Accounting Review, Vol. 10, No. 4, pp. 787-802.

Hooks, K. L., Cheramy, S. J., \& Sincich, T. L. (1994), 'Methods used by big 6 partners in practice development', Auditing: A Journal of Practice and Theory, Vol. 13, No. 1, pp. 101-114.

Hopwood, A. (1974), Accounting and human behaviour, London: Haymarket Publishing.

Huber, G. P. \& Power, D. J. (1985), 'Retrospective reports of strategic-level managers: Guidelines for increasing their accuracy', Strategic Management Journal, Vol. 6, No. 2, pp. 171-180.

Huddart, S. (2013), 'Discussion of Empirical Evidence on the Implicit Determinants of Compensation in Big 4 Audit Partnerships', Journal of Accounting Research, Vol. 51, No. 2, pp. 389-397.

IAASB (2009), International standard on quality control 1 (ISQC 1): Quality control for firms that perform audits and reviews of historical financial information, and other assurance and related services engagements, New York: International Auditing and Assurance Standards Board, International Federation of Accountants.

IAG (2013). Report from the working group on firm governance and incentives. PCAOB Investor Advisory Group, Report presented at Investor Advisory Group (IAG) meeting October 16, 2013, Washington, D.C..

IFIAR (2015). Current trends in the audit industry. International Forum of Independent Audit Regulators.

Kelley, T. \& Margheim, L. (1990), 'The Impact of Time Budget Pressure, Personality, and Leadership Variables on Dysfunctional Auditor Behavior', Auditing: A Journal of Practice \& Theory, Vol. 9, No. 2, pp. 21-42. 
Knechel, W. R., Krishnan, G. V., Pevzner, M., Shefchik, L. B., \& Velury, U. K. (2013a), 'Audit Quality: Insights from the Academic Literature', Auditing: A Journal of Practice \& Theory, Vol. 32, No. Supplement, pp. 385-421.

Knechel, W. R., Niemi, L., \& Zerni, M. (2013b), 'Empirical Evidence on the Implicit Determinants of Compensation in Big 4 Audit Partnerships', Journal of Accounting Research, Vol. 51, No. 2, pp. 349-387.

Kornberger, M., Justesen, L., \& Mouritsen, J. (2011), "'When you make manager, we put a big mountain in front of you": An ethnography of managers in a Big 4 accounting firm', Accounting, Organizations and Society, Vol. 36, No. 8, pp. 514-533.

Korsgaard, M. A. \& Roberson, L. (1995), 'Procedural justice in performance evaluation: The role of instrumental and non-instrumental voice in performance appraisal discussions', Journal of Management, Vol. 21, No. 4, pp. 657-669.

Lambert, T. A. \& Agoglia, C. P. (2011), 'Closing the Loop: Review Process Factors Affecting Audit Staff Follow-Through', Journal of Accounting Research, Vol. 49, No. 5, pp. 1275-1306.

Lewis, M. A. \& Brown, A. D. (2012), 'How different is professional service operations management?', Journal of Operations Management, Vol. 30, No. 1, pp. 1-11.

Lopez, D. M. \& Peters, G. F. (2011), 'Auditor workload compression and busy season auditor switching', Accounting Horizons, Vol. 25, No. 2, pp. 357-380.

Malone, C. F. \& Roberts, R. W. (1996), 'Factors Associated with the Incidence of Reduced Audit Quality Behaviors', Auditing: A Journal of Practice \& Theory, Vol. 15, No. 2, pp. 49-64.

Meyer, J. P. \& Allen, N. J. (1991), 'A three-component conceptualization of organizational commitment', Human resource management review, Vol. 1, No. 1, pp. 61-89. 
Meyer, J. P., Allen, N. J., \& Smith, C. A. (1993), 'Commitment to organizations and occupations: Extension and test of a three-component conceptualization', Journal of applied psychology, Vol. 78, No. 4, pp. 538-551.

Moizer, P. (1992), 'State of the art in audit market research', European Accounting Review, Vol. 1, No. 2, pp. 333-348.

Moreno, K. \& Bhattacharjee, S. (2003), 'The impact of pressure from potential client business opportunities on the judgments of auditors across professional ranks', Auditing: A Journal of Practice \& Theory, Vol. 22, No. 1, pp. 13-28.

Nederhof, A. J. (1985), 'Methods of coping with social desirability bias: A review', European Journal of Social Psychology, Vol. 15, No. 3, pp. 263-280.

Otley, D. T. \& Pierce, B. J. (1995), 'The control problem in public accounting firms: An empirical study of the impact of leadership style', Accounting, Organizations and Society, Vol. 20, No. 5, pp. 405-420.

Otley, D. T. \& Pierce, B. J. (1996a), 'The operation of control systems in large audit firms', Auditing: A Journal of Practice \& Theory, Vol. 15, No. 2, pp. 65-84.

Otley, D. T. \& Pierce, B. J. (1996b), 'Auditor time budget pressure: consequences and antecedents', Accounting, Auditing \& Accountability Journal, Vol. 9, No. 1, pp. 31-58.

PCAOB (2008). Report on the PCAOB's 2004, 2005, 2006, and 2007 Inspections of Domestic Annually Inspected Firms. Public Company Accounting Oversight Board, Washington, D.C..

Pierce, B. \& Sweeney, B. (2004), 'Cost-quality conflict in audit firms: An empirical investigation', European Accounting Review, Vol. 13, No. 3, pp. 415-441.

Pierce, B. \& Sweeney, B. (2005), 'Management control in audit firms: Partners' perspectives', Management Accounting Research, Vol. 16, No. 3, pp. 340-370. 
Pierce, B. \& Sweeney, B. (2006), 'Perceived adverse consequences of quality threatening behaviour in audit firms', International Journal of Auditing, Vol. 10, No. 1, pp. 19-39.

Podsakoff, P. M., MacKenzie, S. B., Lee, J. Y., \& Podsakoff, N. P. (2003), 'Common method biases in behavioral research: a critical review of the literature and recommended remedies', Journal of applied psychology, Vol. 88, No. 5, pp. 879-903.

Pruijssers, J., Van Oosterhout, H., \& Heugens, P. (2013). Organizational Antecedents of Dysfunctional Auditor Behaviors: The Mitigating Role of Audit Firm Governance. Working paper, SSRN 2251828.

Samuel, S., Covaleski, M. A., \& Dirsmith, M. W. (2009). On the eclipse of professionalism in accounting: an essay in C. S. Chapman et al. (Eds) Accounting, Organizations, and Institutions: Essays in honour of Anthony Hopwood, pp. 367-395, Oxford: Oxford University Press.

Stallworth, L. (2004), 'Antecedents and consequences of organizational commitment to accounting organizations', Managerial Auditing Journal, Vol. 19, No. 7, pp. 945-955.

Suddaby, R., Gendron, Y., \& Lam, H. (2009), 'The organizational context of professionalism in accounting', Accounting, Organizations and Society, Vol. 34, No. 3, pp. 409-427.

Svanberg, J. \& Öhman, P. (2015), 'Auditors' identification with their clients: Effects on audit quality', The British Accounting Review, Vol. 47, No. 4, pp. 395-408.

Svanström, T. (2016), 'Time Pressure, Training Activities and Dysfunctional Auditor Behaviour: Evidence from Small Audit Firms', International Journal of Auditing, Vol. 20, No. 1, pp. 42-51.

Sweeney, B. \& Pierce, B. (2004), 'Management control in audit firms: A qualitative examination', Accounting, Auditing \& Accountability Journal, Vol. 17, No. 5, pp. 779812. 
Sweeney, B. \& Pierce, B. (2011), 'Audit team defence mechanisms: auditee influence', Accounting and Business Research, Vol. 41, No. 4, pp. 333-356.

Sweeney, B., Pierce, B., \& Arnold, D. (2013), 'The Impact of Perceived Ethical Intensity on Audit-Quality-Threatening Behaviours', Accounting and Business Research, Vol. 43, No. 2, pp. 112-137.

Trompeter, G. (1994), 'The effect of partner compensation schemes and generally accepted accounting principles on audit partner judgment', Auditing: A Journal of Practice \& Theory, Vol. 13, No. 2, pp. 56-68.

Westermann, K., Bedard, J. C., \& Earley, C. E. (2015), 'Learning the 'Craft' of Auditing: A Dynamic View of Auditors' On-the-Job Learning', Contemporary Accounting Research, Vol. 32, No. 3, pp. 864-896.

Wyatt, A. R. (2004), 'Accounting Professionalism-They Just Don't Get It!', Accounting Horizons, Vol. 18, No. 1, pp. 45-53.

Zeff, S. A. (2003a), 'How the US Accounting Profession Got Where It Is Today: Part I', Accounting Horizons, Vol. 17, No. 3, pp. 189-206.

Zeff, S. A. (2003b), 'How the US Accounting Profession Got Where It Is Today: Part II', Accounting Horizons, Vol. 17, No. 4, pp. 267-287. 


\section{APPENDIX 1. QUESTIONNAIRE}

\section{Measures included in the Performance Evaluation}

Please consider the importance of the following items when superiors evaluate your performance. Response scale from 1 (not important) to 7 (highly important).

\section{Efficiency orientation}

a. Fixed-fee/costs - the extent to which costs are covered by the audit fee.

b. Your ability to meet the budget.

c. Share of billable hours (relative to total working hours).

d. Your ability to minimize time registered on the engagements in which you are involved.

\section{Client orientation}

e. Your ability to sell non-audit services.

f. Customer evaluations of your work.

g. Your ability to win new clients.

\section{Quality orientation}

h. Your ability to comply with the audit methodology of the firm and other internal regulations.

i. The extent to which deficiencies have been identified in quality control inspections of the engagements with which you are involved.

j. Assessments of your professional competences and development.

k. Your ability to identify and solve problems.

\section{Dysfunctional Behaviour}

Below is a list of situations which represent pressure that auditors in other audit firms claim to have experienced in their work. To what extent have you experienced these situations? Response scale from 1 (never) to 7 (almost always). 
a. Taking actions that enhance the short-term performance of the firm even though it may negatively impact long-term performance.

b. Skipping a required procedure.

c. Taking actions that are against your better professional judgement.

d. Being unable to record all the time spent on the work that is assigned to you.

e. Having to stay longer hours in the office to indicate to your superior or colleagues that you are working hard.

f. Laws, standards or internal regulations that are rigid or burdensome to such an extent that it is appropriate to avoid or skip a procedure.

\section{Organizational Commitment}

To what extent do you agree with the statements below? Response scale from 1 (strongly disagree) to 7 (strongly agree).

a. I would be very happy to spend the rest of my career with this organization.

b. I really feel as if this organization's problems are my own.

c. I think that it would be just as easy for me to feel 'emotionally attached' to another audit firm (reverse-coded).

d. I do not feel that it is possible for me to leave my current employer for another.

e. One of the central reasons for staying with my current employer is that too much of my life would be disrupted if I quit - the benefits I have here would be difficult to obtain elsewhere.

f. I do not feel any obligation to remain with my current employer (reverse-coded).

g. This organization deserves my loyalty.

h. I would not leave my organization right now because I have a sense of obligation to the people in it.

i. I really care about the future of this organization. 
TABLE 1: CFA $(n=196)$

\begin{tabular}{l}
\hline \\
Average variance extracted (AVE) \\
Composite reliability \\
Item a. Taking actions that enhance the short-term performance of the firm even though it may \\
negatively impact long-term performance \\
Item b. Skipping a required procedure \\
Item c. Taking actions that are against your better professional judgement \\
Item d. Being unable to record all the time spent on the work that is assigned to you \\
Item e. Having to stay longer hours in the office to indicate to your superior or colleagues that you \\
are working hard \\
Item f. Laws, standards or internal regulations that are rigid or burdensome to such an extent that it is \\
appropriate to avoid or skip a procedure
\end{tabular}

Average variance extracted (AVE)

Item a. Fixed-fee/costs - the extent to which costs are covered by the audit fee

Composite reliability

Item b. Your ability to meet the budget

Item c. Share of billable hours (relative to total working hours)

Item d. Your ability to minimize time registered on the engagements in which you are involved

Average variance extracted (AVE) Composite reliability

Item e. Your ability to sell non-audit services

Item f. Customer evaluations of your work

Item g. Your ability to win new clients

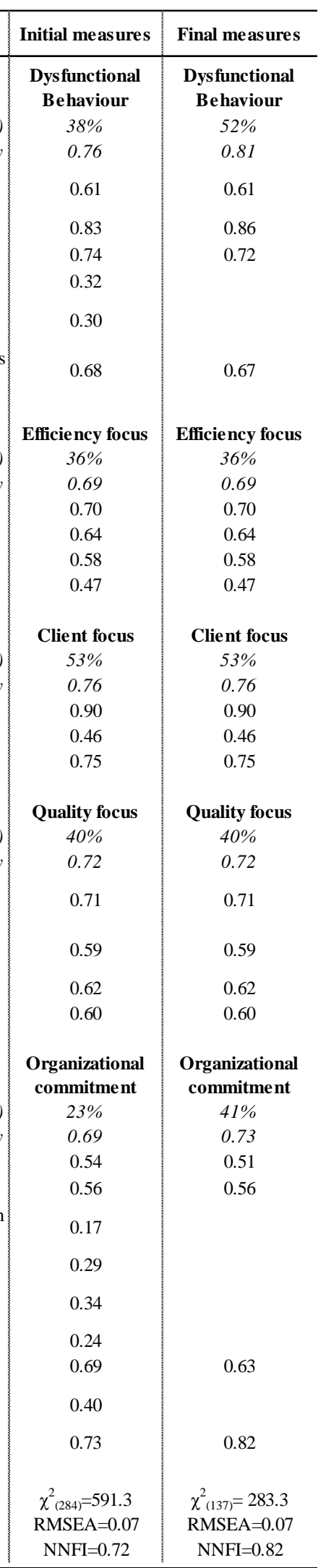

Item a. I would be very happy to spend the rest of my career with this organization

Average variance extracted (AVE) Composite reliability

Item b. I really feel as if this organization's problems are my own

Item c. I think that it would be just as easy for me to feel 'emotionally attached' to another audit firm (reverse-coded)

Item d. I do not feel that it is possible for me to leave my current employer for another Item e. One of the central reasons for staying with my current employer is that too much of my life would be disrupted if I quit - the benefits I have here would be difficult to obtain elsewhere Item f. I do not feel any obligation to remain with my current employer (reverse-coded) Item g. This organization deserves my loyalty

Item h. I would not leave my organization right now because I have a sense of obligation to the people in it

Item i. I really care about the future of this organization

\section{Composite reliability}

Item h. Your ability to comply with the audit methodology of the firm and other internal regulations

Item i. The extent to which deficiencies have been identified in quality control inspections of the engagements with which you are involved

Item j. Assessments of your professional competences and development

Item k. Your ability to identify and solve problems 
TABLE 2: Descriptive Statistic

\begin{tabular}{|c|c|c|c|c|c|c|c|c|c|c|c|c|c|c|c|c|c|c|c|c|}
\hline & & & & & & & & CABLE & 2: Descripti & ve Statis & & & & & & & & & & \\
\hline & \multirow[b]{3}{*}{$\begin{array}{l}\text { Theoretical } \\
\text { range }\end{array}$} & \multicolumn{12}{|c|}{ Panel A: Range, mean, S.D and Cronbach's alpha } & \multirow{2}{*}{\multicolumn{7}{|c|}{$\begin{array}{c}\text { Panel B: Correlations } \\
\text { Full sample (n=196) }\end{array}$}} \\
\hline & & \multicolumn{4}{|c|}{ Full sample (n=196) } & \multicolumn{4}{|c|}{ Staff auditors $(\mathrm{n}=101)$} & \multicolumn{4}{|c|}{ Managers $(\mathrm{n}=95)$} & & & & & & & \\
\hline & & $\begin{array}{l}\text { Actual } \\
\text { range }\end{array}$ & Mean & S.D. & $\begin{array}{c}\text { Cronbach's } \\
\text { alpha }\end{array}$ & $\begin{array}{l}\text { Actual } \\
\text { range }\end{array}$ & Mean & S.D. & $\begin{array}{c}\text { Cronbach's } \\
\text { alphha }\end{array}$ & $\begin{array}{l}\text { Actual } \\
\text { range }\end{array}$ & Mean & S.D. & $\begin{array}{c}\text { Cronbach's } \\
\text { alpha }\end{array}$ & 1 & 2 & 3 & 4 & 5 & 6 & 7 \\
\hline 1 Dysfunctional behaviour & $4-28$ & $4-24$ & 11.02 & 4.68 & 0.80 & $4-21$ & 10.94 & 4.49 & 0.80 & $4-24$ & 11.11 & 4.89 & 0.81 & & & & & & & \\
\hline 2 Efficiency focus & $4-28$ & $8-28$ & 20.19 & 3.78 & 0.68 & $8-28$ & 19.62 & 4.04 & 0.73 & $14-28$ & 20.79 & 3.40 & 0.61 & 0.03 & & & & & & \\
\hline 3 Client focus & $3-21$ & $3-21$ & 12.38 & 3.63 & 0.73 & $3-21$ & 11.31 & 3.85 & 0.75 & $6-21$ & 13.52 & 3.01 & 0.62 & $0.13^{*}$ & $0.28+* *+$ & & & & & \\
\hline 4 Quality focus & $4-28$ & $12-28$ & 20.42 & 3.37 & 0.72 & $12-28$ & 20.04 & 3.23 & 0.73 & $13-28$ & 20.82 & 3.49 & 0.72 & $-0.26+* *$ & $0.28+* *+$ & $0.28 *+*$ & & & & \\
\hline 5 Organizational commitment & $4-28$ & $4-28$ & 18.21 & 4.37 & 0.72 & $7-27$ & 18.05 & 4.11 & 0.69 & $4-28$ & 18.38 & 4.66 & 0.75 & $-0.21+* *$ & $0.15 *$ & & $0.31+* *$ & & & \\
\hline 6 Big 4 & $0-1$ & $0-1$ & 0.47 & 0.50 & $\mathrm{NA}$ & $0-1$ & 0.45 & 0.50 & $\mathrm{NA}$ & $0-1$ & 0.51 & 0.50 & $\mathrm{NA}$ & $-0.03-2$ & $-0.13^{*}$ & $0.15 *$ & -0.06 & $-0.14^{*}$ & & \\
\hline 7 Experience & $\mathrm{NA}$ & $1-39$ & 7.94 & 7.63 & $\mathrm{NA}$ & $1-39$ & 5.58 & 6.37 & $\mathrm{NA}$ & $2-37$ & 10.45 & 8.07 & $\mathrm{NA}$ & $-0.17^{* *}$ & 0.08 & $0.32 *+*$ & 0.11 & $0.16 *$ & $-0.24 *+*$ & \\
\hline 8 Manager & $0-1$ & $0-1$ & 0.48 & 0.50 & $\mathrm{NA}$ & & & & & & & & & 0.02 & $0.15^{* *}$ & $0.30^{*+*}$ & 0.12 & 0.04 & 0.06 & $0.32+\cdots+$ \\
\hline
\end{tabular}

TABLE 3

Regression Results for Dysfunctional Behaviour Regressed on Evaluation Foci

\begin{tabular}{|c|c|c|c|c|c|c|}
\hline & \multicolumn{2}{|c|}{ Full sample } & \multicolumn{2}{|c|}{ Staff auditors } & \multicolumn{2}{|c|}{ Managers } \\
\hline & $\beta$ & $\mathrm{t}$ & $\beta$ & $\mathrm{t}$ & $\beta$ & $\mathrm{t}$ \\
\hline \multicolumn{7}{|l|}{ EXPLANATORY VARIABLES } \\
\hline Efficiency focus, $\mathrm{H1}(+)$ & 0.04 & 0.47 & 0.06 & 0.61 & 0.06 & 0.39 \\
\hline Client focus, H2(+) & $0.44 * * *$ & 4.26 & $0.53 * * *$ & 4.24 & 0.20 & 1.02 \\
\hline Quality focus, H3(-) & $-0.35 * * *$ & -4.54 & $-0.33 * * *$ & -3.40 & $-0.37 * * *$ & -3.29 \\
\hline \multicolumn{7}{|l|}{ CONTROL VARIABLES } \\
\hline Organizational commitment & -0.16 & -1.64 & -0.14 & -1.30 & -0.14 & -0.96 \\
\hline Big 4 & $-1.16 * *$ & -2.14 & -0.50 & -0.69 & $-1.77 * *$ & -2.61 \\
\hline Experience & $-0.12 * * *$ & -2.62 & -0.03 & -0.44 & $-0.18 * * *$ & -5.16 \\
\hline Manager & 0.37 & 0.71 & & & & \\
\hline $\mathrm{n}$ & 196 & & 101 & & 95 & \\
\hline $\mathrm{R}^{2}$ & 0.20 & & 0.19 & & 0.29 & \\
\hline Adjusted $\mathrm{R}^{2}$ & 0.17 & & 0.14 & & 0.24 & \\
\hline $\mathrm{F}$ & $6.58 * * *$ & & $3.77 * * *$ & & $5.95 * * *$ & \\
\hline
\end{tabular}

${ }^{*} p<0.10 ;{ }^{* *} \mathrm{p}<0.05 ;{ }^{* * *} \mathrm{p}<0.01$ (two-tailed) 
TABLE 4

Regression Results for Individual Dysfunctional Behaviour Items Regressed on Evaluation Foci

\begin{tabular}{|c|c|c|c|c|c|c|c|c|c|c|c|c|}
\hline & \multicolumn{2}{|c|}{ Item a } & \multicolumn{2}{|c|}{ Item b } & \multicolumn{2}{|c|}{ Item c } & \multicolumn{2}{|c|}{ Item d } & \multicolumn{2}{|l|}{ Item e } & \multicolumn{2}{|c|}{ Item $\mathrm{f}$} \\
\hline & $\beta$ & $\mathrm{t}$ & $\beta$ & $\mathrm{t}$ & $\beta$ & $\mathrm{t}$ & $\beta$ & $\mathrm{t}$ & $\beta$ & $\mathrm{t}$ & $\beta$ & $\mathrm{t}$ \\
\hline \multicolumn{13}{|l|}{ EXPLANATORY VARIABLES } \\
\hline Efficiency focus, $\mathrm{H} 1(+)$ & 0.03 & 1.29 & -0.01 & -0.46 & -0.01 & -0.40 & 0.02 & 0.67 & 0.04 & 1.33 & 0.03 & 1.09 \\
\hline Client focus, H2(+) & $0.07 * *$ & 2.20 & $0.15 * * *$ & 4.54 & $0.10 * * *$ & 2.83 & 0.06 & 1.56 & 0.02 & 0.70 & $0.12 * * *$ & 3.62 \\
\hline Quality focus, H3(-) & $-0.08 * * *$ & -3.27 & $-0.12 * * *$ & -4.92 & $-0.08 * * *$ & -2.88 & 0.00 & 0.13 & -0.02 & -0.86 & $-0.07 * * *$ & -2.97 \\
\hline \multicolumn{13}{|l|}{ CONTROL VARIABLES } \\
\hline Organizational commitment & -0.01 & -0.43 & -0.04 & -1.50 & $-0.05 *$ & -1.79 & $-0.05 *$ & -1.83 & 0.01 & 0.46 & $-0.05 *$ & -1.76 \\
\hline Big 4 & -0.05 & -0.29 & $-0.31 * *$ & -2.01 & $-0.40 * *$ & -2.33 & -0.09 & -0.58 & -0.03 & -0.20 & $-0.40 * *$ & -2.28 \\
\hline Experience & $-0.03 * *$ & -2.35 & $-0.05 * * *$ & -4.32 & -0.02 & -1.50 & 0.00 & -0.43 & $-0.05 * * *$ & -5.75 & $-0.02 *$ & -1.71 \\
\hline Manager & 0.17 & 1.02 & $0.28 *$ & 1.82 & -0.03 & -0.16 & -0.01 & -0.07 & -0.13 & -0.89 & -0.05 & -0.30 \\
\hline n & 196 & & 196 & & 196 & & 196 & & 196 & & 196 & \\
\hline $\mathrm{R}^{2}$ & 0.10 & & 0.24 & & 0.11 & & 0.04 & & 0.16 & & 0.13 & \\
\hline Adjusted $\mathrm{R}^{2}$ & 0.06 & & 0.21 & & 0.08 & & 0.00 & & 0.12 & & 0.10 & \\
\hline $\mathrm{F}$ & $2.83 * * * *$ & & $8.42 * * *$ & & $3.32 * * *$ & & 1.07 & & $4.95 * * * *$ & & $4.03 * * *$ & \\
\hline
\end{tabular}

${ }^{*} p<0.10 ;{ }^{* *} \mathrm{p}<0.05 ; * * * \mathrm{p}<0.01$ (two-tailed) 